xylem in one or two year old stems. The average depth of the latter almost always equals and usually exceeds that of the former (fig. I), indicating conclusively that there is no growth acceleration in the convex arcs of the cambium which form the projecting wedges. As has been indicated by the writer, the undulating outline of the first formed secondary xylem is due to the stellate arrangement of the primary elements, and consequently the stellate outline of the first formed cambium. However, this originally lobed cambium rapidly takes on a circular outline, owing to the slower growth of its convex projecting arcs, except in stems which have a hereditary tendency for the formation of pairs of approximated multiseriate rays.-I. W. BAILEx, Bussey Institution, Jamaica Plain, Mass.

\title{
IMPORTANCE OF EPIDERMAL COVERINGS
}

(WITH TWO FIGURES)

In making tests of the relative resistance of some herbaceous plants to freezing, it was observed that inoculation from ice formed on the leaf surface was a factor of great importance in determining the temperature at which ice formation occurred in the leaf tissue. In testing cabbages it was observed that the greatest undercooling of the tissue below its freezing point occurred in those plants which had the greatest amount of "bloom" on the leaf surface. Plants well covered by wax could be maintained for hours at a temperature $5^{\circ} \mathrm{C}$. below their freezing point without the formation of ice in the tissues. Similar conditions were found to occur in the common Cineraria and other such plants which are densely covered with a mat of epidermal hairs. This condition suggested that inoculation of the undercooled leaf tissue by ice formed on the leaf surface was an important factor in frost resistance. The object of this study was to determine the amount of undercooling which can occur in such tissues, and the importance of the epidermal coverings in preventing surface inoculation of the undercooled tissues.

The thermoelectric method was used to measure temperatures, since this method allows one to determine the temperature inside rather thin leaves. A copper-constantan couple of no. $40 \mathrm{~B}$. and S. gauge which had a thermal coefficient of 3.33 millivolts per degree Centigrade was used. Using such a couple the delicacy of the potentiometer arrangement determines the accuracy of the temperature measurement. Although with the arrangement used much smaller changes could be

${ }^{1}$ Published by permission of the Secretary of Agriculture. 
determined, measurements to $\circ . \mathrm{I}^{\circ} \mathrm{C}$. or less were found to be sufficiently accurate for this work.

Fig. I shows the arrangement for temperature measurement as well as the means for securing undercooling of the tissues. Directions for

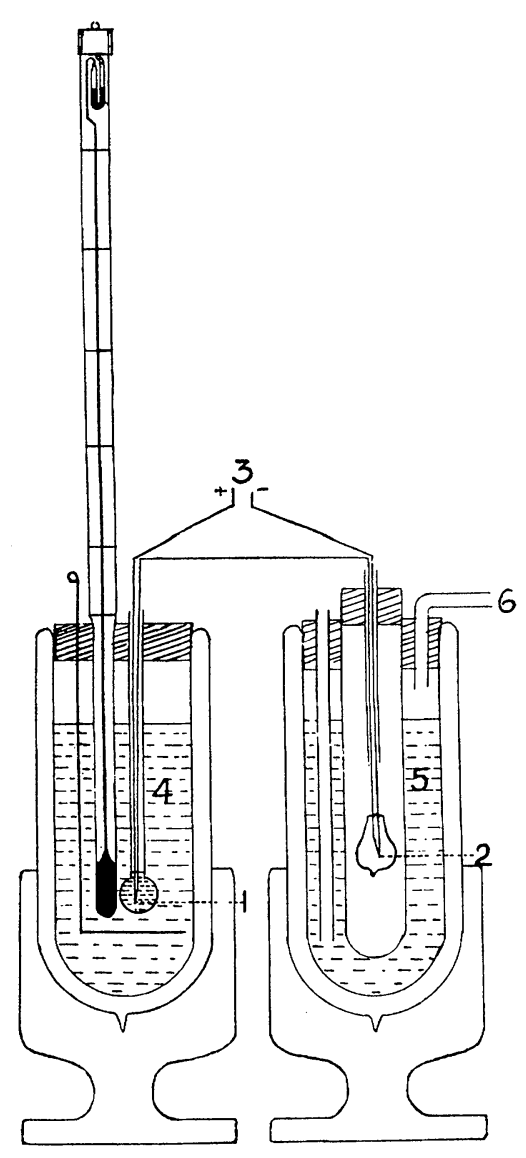

FIG. I constructing the thermal junctions are to be found in the publications of White from the Carnegie Institution of Washington. ${ }^{2}$ The constant temperature junction of the thermocouple was placed in a thinwalled tube filled with oil and immersed in a slush of clean snow in distilled water contained in a Dewar beaker. It was found that the temperature of this junction could be kept constant for a long time within a few thousandths of a degree Centigrade, as shown by a standard Beckmann thermometer. In calibrating the couple, the junction to be placed within the leaf was placed in a Dewar beaker similar to the former arrangement, with solutions having freezing points a few degrees below zero.

A number of tissues were tested with this apparatus, including carnation stem, cabbage leaf, Echeveria leaves, Cineraria petiole, tomato petiole, and others. In general the results show that plants with heavy epidermal coverings of wax or trichomes can undergo a much greater undercooling than such plants as tomatoes, in which the epidermal walls are thin and nonresistant.

${ }^{2}$ WhITE, W. P., The thermoelement as a precision thermometer. Physical Review 31:135. I9IO.

- - The constancy of thermoelements. Physical Review 23:449. 1906.

White, W. P., Dickinson, H. C., and Mueller, E. I. The calibration of copper-constantan thermoelements. Physical Review 3I:I59. I9IO. 
To make certain that all of the samples should have ice formed on the surface, a small drop of water was placed on each. To test the effect of the epidermal covering in preventing inoculation, samples of the same material were cooled with the coverings intact, and also after they had been removed. Precautions were taken to prevent the inoculation of the tissue from juices exuded at cut surfaces. In all cases the cut surfaces were dried and covered with vaseline, which procedure was found to prevent such an inoculation of the tissue. In all the tests it was

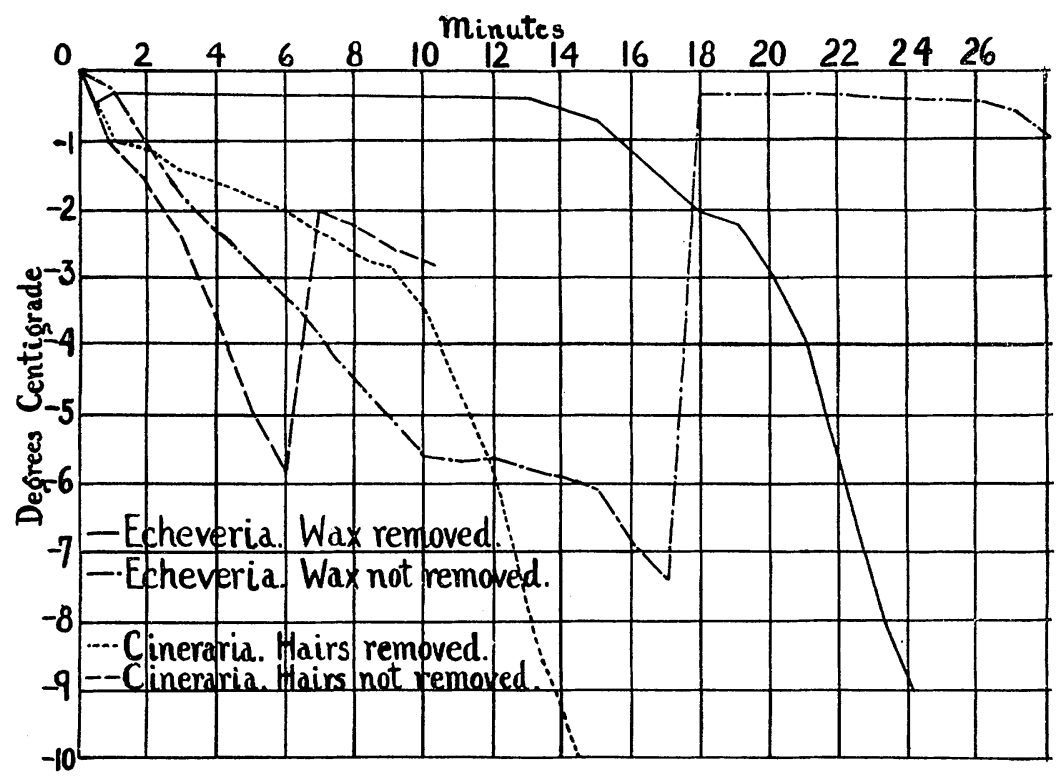

FIG. 2

found that when thick epidermal coverings were unbroken, undercooling occurred, while in those cases where they were removed but little undercooling occurred.

Fig. 2 shows typical cooling curves, indicating the importance of the epidermal coverings in preventing ice formation within the tissue. It appears that the tissue without the protective covering is unable to undergo any great amount of undercooling. This depends in part upon the amount of shaking of the tissue. The osmotic concentration or the presence of colloidal substances in solution in the cell sap are of relatively minor importance in determining the undercooling. 
It has been observed during spring frosts that in blooming apricots those buds which have opened and are turned upward to collect snow are frozen, while those turned downward may not be injured. West and EDLEFSEN ${ }^{3}$ attempted to prevent frost injury to apricot buds by spraying the trees with water. Instead of the desired effect of preventing freezing, this procedure evidently killed the tissue by allowing inoculation from ice formed on the surface. Trees which were not sprayed with water were not injured, although subjected to the same temperature. These examples serve to illustrate the importance of surface inoculation in producing frost injury.

The amount of undercooling in plants is not generally very great, nor is it sufficient to account for true frost hardiness. Such herbaceous plants as cabbage, kale, turnips, however, which ordinarily can withstand a considerable degree of freezing, acquire hardiness quite rapidly. In the case of cabbage, a temperature of $3^{\circ} \mathrm{C}$. was found to harden the plants sufficiently in 5 days to allow them to be frozen stiff at $-3^{\circ} \mathrm{C}$. without injury. The principal importance, therefore, of the epidermal coverings for the frost resistance of such plants appears to be that they allow the plants which possess them to withstand temperatures somewhat below zero until the cells are able to adapt themselves physiologically to the changes incident upon freezing.

\section{Summary}

Undercooling of the tissues occurs to a greater degree in such herbaceous plants as possess protective epidermal coverings than in plants not so protected. The undercooling in such plants is not due to substances in the cell sap, but mainly to the prevention of inoculation from ice formed on the surface of the tissue. A method is given for determining electrically the temperatures within leaf tissues.-R. B. HARvey, Bureau of Plant Industry, Department of Agriculture, Washington, D.C.

3 West, F. S., and EdLefsen, N. E., Orchard heating. Bull. I6I, Utah Agric. Coll. Exp. Sta. I9 7 . 